\title{
A Maximum Transfer Efficiency Tracking Method for Dynamic Wireless Charging Systems of Electric Vehicles
}

\author{
Nguyen Kien Trung ${ }^{1}$ and Nguyen Thi Diep (D) $^{2}$ \\ ${ }^{1}$ School of Electrical Engineering, Hanoi University of Science and Technology, Hanoi 100000, Vietnam \\ ${ }^{2}$ Faculty of Control and Automation, Electric Power University, Hanoi 100000, Vietnam \\ Correspondence should be addressed to Nguyen Thi Diep; diepnt@epu.edu.vn
}

Received 10 February 2021; Revised 25 October 2021; Accepted 5 November 2021; Published 23 November 2021

Academic Editor: Pascal Venet

Copyright (C) 2021 Nguyen Kien Trung and Nguyen Thi Diep. This is an open access article distributed under the Creative Commons Attribution License, which permits unrestricted use, distribution, and reproduction in any medium, provided the original work is properly cited.

\begin{abstract}
This paper proposes a new control method to improve transfer efficiency for dynamic wireless charging systems of electric vehicles (EVs). In the charging process, the equivalent impedance in the receiving side varies according to the state of charge of the battery system that reduces the transfer efficiency. An impedance control circuit is constructed on the receiving side to track the optimization impedance that transfer efficiency is maximized. However, the optimization impedance depends on the coupling coefficient. Therefore, in this paper, the coupling coefficient, which varies according to the EVs position, is online estimated only from the receiving side. A $1.5 \mathrm{~kW}$ dynamic wireless charging system prototype is built in the laboratory environment. In experiment results, the greatest transfer efficiency obtains $94.14 \%$ when the EVs move in aligned on the charging lane. Furthermore, the proposed control method improves by $6 \%$ on the transfer efficiency in the case of $30 \%$ misalignment when the transfer efficiency obtains $91 \%$.
\end{abstract}

\section{Introduction}

Recently, electric vehicles (EVs) are considered as a green solution to reduce the air pollution problem in big cities in the world. However, the use of EVs is still limited due to the charging infrastructure. The wire charging system is inconvenient [1-3]. Based on the wireless power transfer (WPT) technology, the wireless charging system promises a convenient charging solution for EVs [4, 5]. Wireless charging systems for EVs are classified into two categories: static wireless charging (SWC) and dynamic wireless charging (DWC). The SWC system has been rapidly developed in the last decade, some commercial products have appeared in the market [2]. However, the big battery capacity and the static charging requirement still are the disadvantages [3]. In the DWC systems, the EVs can be continuously charged while moving. The driving range of the EV can be extended, and a smaller battery pack can be used to reduce the vehicle weight as well as the vehicle cost [3-5]. Now, the dynamic wireless charging system is an attractive research topic. Scientists almost focus on efficiency improvement and high-power charging system design [6-10].

The transfer efficiency of WPT systems depends on the coils design, compensation circuit design, operating frequency, and load impedance [1]. However, with a certain DWC system, the coils, the compensation circuits, and the operating frequency are fixed. Then, the impedance matching control is very important to obtain high transfer efficiency. The impedance matching can be done by tuning the compensation circuit [11-15], by using DC/DC converter [16-18], and by controlling the input power to track the maximum efficiency point [19-23]. However, all the research considers the optimal load is a constant value suitable for the SWC system. In the DWC systems, the receiving coil is moving, then the coupling coefficient is changing, and the optimal load value is not constant 
[24-29]. Therefore, to realize the impedance matching control, the optimal load must be identified previously. In other words, the continuous estimation of the coupling coefficient is needed.

The coupling coefficient estimation has been done by some researchers. References [25-28] present a real-time coupling coefficient estimation method applying for a dynamic charging system. Only the secondary side parameters are needed to measure. However, measuring the RMS value of alternating current takes error in the discontinuous current mode. The coupling coefficient can be estimated using the DC side measurement parameters [25, 29]. However, their studies consider a simple dynamic charging system where there is only one transmitting coil and one receiving coil. Furthermore, the analysis and results are done only in the case when the receiving coil moves in the center of the transmitting coil. Reference [30] shows a coupling coefficient identification method by switching the compensation capacitors. However, the estimation equations require the information of the resonant currents on primary and secondary sides, which will increase the difficulty in practice.

This paper proposes a maximum transfer efficiency method in the DWC system through the compensation circuit design and optimal impedance load tracking control. The coupling system includes three transmitting coils and one receiving coil. The coupling coefficient is estimated by measuring only the DC parameters on the receiving side. Firstly, the coupling coefficient of the DWC system is analyzed. Secondly, the double-sided LCC compensation circuit is designed to obtain maximum efficiency. Thirdly, the optimal load is calculated through the estimation coupling coefficients from the secondary side. Finally, an impedance controller is proposed to track the optimal load impedance based on a DC/DC converter.

The control concept and the stability analysis are provided, and its effectiveness is verified by simulation and experiments. The experiment results show that when the EV moves along the charging lane with no misalignment, the transfer efficiency of over $94.14 \%$ is obtained. Moreover, when the EV moves in a 30\% misalignment from the center of the transmitting coil, the transfer efficiency could improve by $6 \%$ by applying the proposed control method.

\section{The Theoretical Basis for Maximum Transfer Efficiency Tracking Method}

2.1. System Structure. Figure 1 shows the structure of the proposed DWC of EVs, which consists of the primary side on the road and the secondary side attached to the EV. The input DC voltage is inverted to an $85 \mathrm{kHz}$ AC voltage by a voltage source type full-bridge inverter. The power is transferred from the primary side to the secondary side through the magnetic coupling system. Then, the obtained AC voltage on the receiving coil is rectified to DC voltage and through DC/DC converters supply to the EV.

On the primary side, one transmitting modular includes three transmitting coils powered by a single inverter to reduce the number of the inverter. And each transmitter coil is compensated individually by its LCC compensation circuit. Several modules are placed continuously on the road which is called the DWC lane. On the secondary side, the receiving coil is mounted under the $\mathrm{EV}$ chassis to receive the energy from the charging lane. On this side, the LCC compensation circuit is also used. A single-phase diode rectifier and a boost converter are used to track the optimal impedance from the secondary side. After that, a DC-DC converter is used to control the battery charging process.

\subsection{Analysis of the System's Coupling Coefficient} Characteristics. In this system, the magnetic coupler is designed by finite element analysis (FEA) simulation to reduce power pulsation [31]. The magnetic coupler is designed with three layers: the first layer is rectangular unipolar coils. The second layer is the ferrite bars; it is used to conduct the magnetic field and strengthen the magnetic connection between the transmitting coils and the receiving coil. The third layer is an aluminum shield, which protects the magnetic field from leaking into the environment. Each transmitting modular consists of three unipolar coils ( $T 1$, T2, T3) placed side by side to reduce the power pulsation. The dimension of each transmitting coil and receiving coil is $400 \mathrm{~mm} \times 400 \mathrm{~mm} \times 42 \mathrm{~mm}$ and $500 \mathrm{~mm} \times 400 \mathrm{~mm} \times$ $42 \mathrm{~mm}$, respectively, in which each coil has 10 turns. The air gap distance between the transmitting coils and receiving coil is $150 \mathrm{~mm}$. The structure of the magnetic coupler is shown in Figure 2.

When the receiver moves on the DWC lane, the receiver displacement according to $x$-direction is defined as $d r$, which is zero when the receiver is centered on the first transmitter (T1). The receiver lateral misalignment according to $y$-direction is defined as $l m$, which is zero when the receiver is straight with the transmitters.

The FEA simulation result of the coupling coefficients when the receiver moves on the DWC lane is shown in Figure 3 (solid lines). The total coupling coefficient between the receiving coil and transmitting coils is defined as $k_{r}$. When the receiver moves along the DWC lane according to the $x$-direction and lateral misalignment in 3 cases, $l_{m}=0 \mathrm{~mm}, l_{m}=40 \mathrm{~mm}, l_{m}=60 \mathrm{~mm}$, the average coefficient coupling is equal to $0.14,0.111$, and 0.078 , respectively. This result shows that when lateral misalignment increases, the total coupling coefficient decreases.

The FEA simulation results of the self-inductance and mutual-inductance values of the transmitters and receiver are shown in Table 1. The total mutual-inductance of transmitter $T_{i}(i=1,2,3)$ with other transmitters is defined as $M_{i} . L_{i} ; L_{r}$ is self-inductance of the transmitting coils and receiving coil.

\subsection{Optimal Load Conditions to Maximize Transfer Efficiency.} In this system, the LCC compensation circuit is designed for both the transmitting and receiving sides [29]. The LCC compensation circuit has many advantages such as high efficiency with both heavy and light loads and resonant frequency regardless of the coupling coefficient and load 


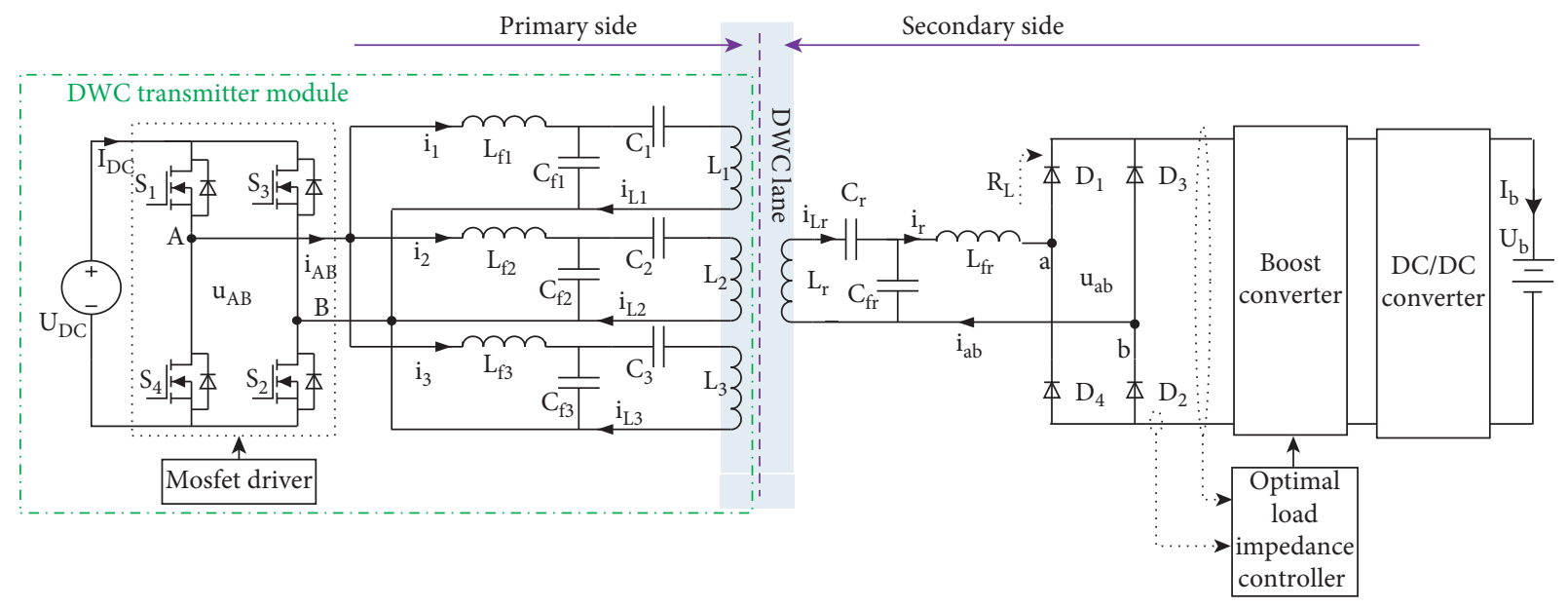

FIGURE 1: Structure diagram of the designed DWC system.

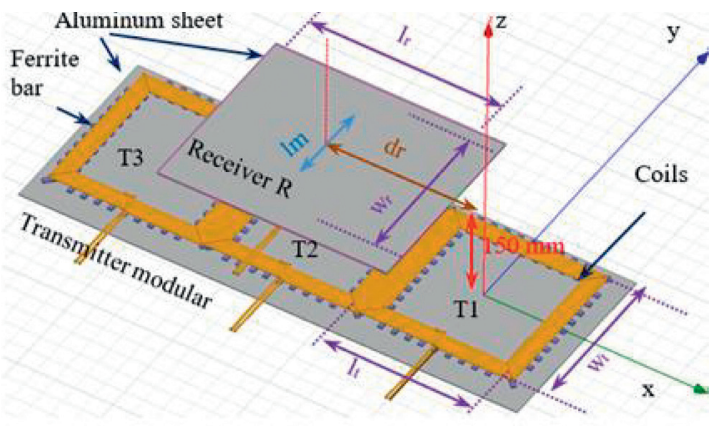

Figure 2: Magnetic coupler structure.

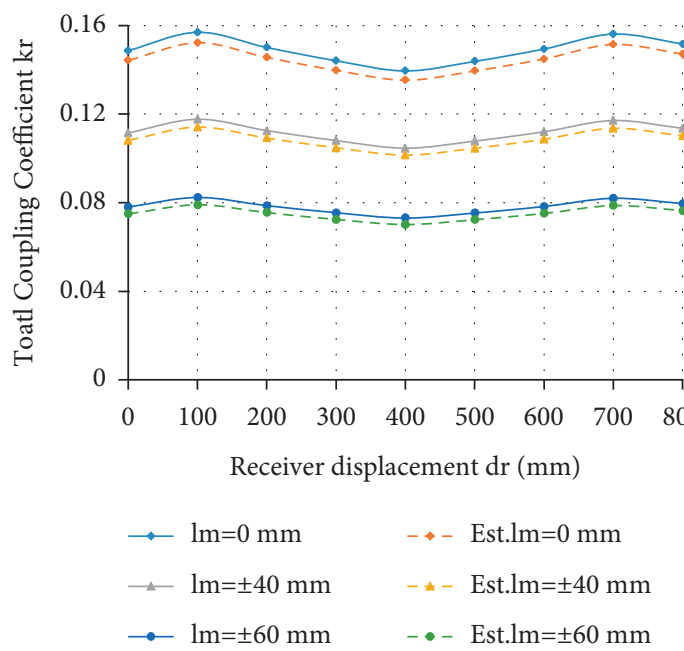

FIgURE 3: Simulation and estimation result of the total coupling coefficient.

TABLE 1: The self-inductance and mutual-inductance values of the transmitters and receiver.

\begin{tabular}{lccc}
\hline Parameter & Value $(\mu \mathrm{H})$ & Parameter & Value $(\mu \mathrm{H})$ \\
\hline$L_{i}(i=1,2,3)$ & 102 & $M_{1}$ & 12.474 \\
$L_{r}$ & 120 & $M_{2}$ & 20.903 \\
& & $M_{3}$ & 12.474 \\
\hline
\end{tabular}




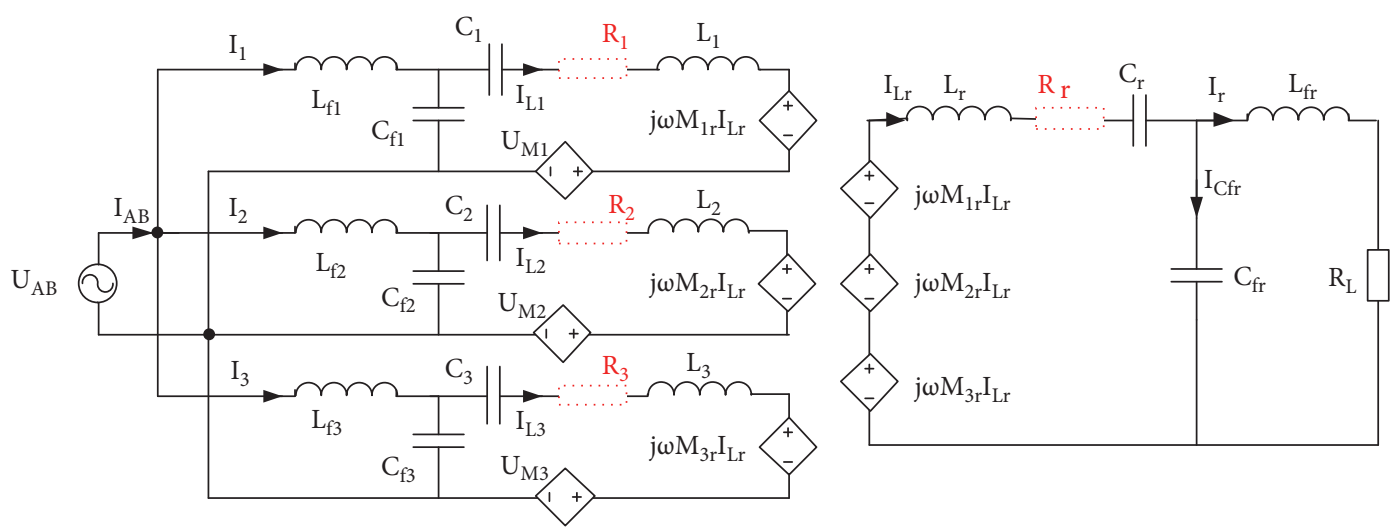

FIgURE 4: Equivalent circuit of the coupling system.

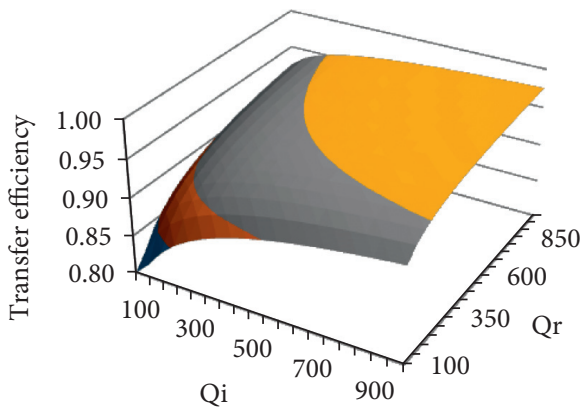

- $0.95-1.00$

- $0.90-0.95$

- $0.85-0.90$

- $0.80-0.85$

FIGURE 5: Maximum theoretical transfer efficiency characteristic with $k_{r}=0.14$.

$[8,10]$. The LCC compensation circuit is designed with consideration of the self-coupled of the transmitting coils together [31]. The resonant frequency of the coupling system is designed the same as the switching frequency of the inverter. The primary side compensation circuits are used to reduce the volt-ampere rating of the power converter and help achieve soft switching of power switches on the high- frequency inverter. The secondary side compensation circuit is used to enhance power transfer capability.

The equivalent circuit of the coupling system is shown in Figure 4, where all of the circuits from the diode rectifier to the battery on the secondary side are considered equivalent impedance $\left(R_{L}\right)$. Then, the transfer efficiency can be calculated as follows [31]:

$$
\begin{aligned}
\eta & =\frac{R_{L} I_{r}^{2}}{R_{L} I_{r}^{2}+R_{r} I_{L r}^{2}+R_{1} I_{L 1}^{2}+R_{2} I_{L 2}^{2}+R_{3} I_{L 3}^{2}} \\
& =\frac{R_{L}}{R_{L}^{2} \cdot\left(R_{r} / \omega^{2} L_{f r}^{2}\right)\left(3+k_{r}^{2} Q_{i} Q_{r} / k_{r}^{2} Q_{i} Q_{r}\right)+R_{L}\left(1+\left(6 / k_{r}^{2} Q_{i} Q_{r}\right)\right)+\left(3 \omega^{2} L_{f r}^{2} / R_{r}\right)\left(1 / k_{r}^{2} Q_{i} Q_{r}\right)},
\end{aligned}
$$

where $Q_{i}=\omega L_{i} / R_{i}, Q_{r}=\omega L_{r} / R_{r}$ is the quality factor of the transmitting coils and receiving coil. Equation (1) shows that, with a designed system, the transfer efficiency depends on the coupling coefficient $\left(k_{r}\right)$, switching frequency $\left(f_{s w}\right)$, and equivalent impedance $\left(R_{L}\right)$. Then, the optimal load for maximum transfer efficiency can be obtained as

$$
\begin{gathered}
\eta_{\max }=\frac{k_{r}^{2} Q_{i} Q_{r}}{\left(\sqrt{3}+\sqrt{3+k_{r}^{2} Q_{i} Q_{r}}\right)^{2}}, \\
R_{\text {L.opt }}=\frac{\omega^{2} L_{f r}^{2}}{R_{r}} \sqrt{\frac{3}{3+k_{r}^{2} Q_{i} Q_{r}}},
\end{gathered}
$$


TABLE 2: System and compensation circuit parameter.

\begin{tabular}{|c|c|c|c|c|c|}
\hline Parameter & Value & Parameter & Value & Parameter & Value \\
\hline$P_{0}$ & $1.5 \mathrm{~kW}$ & $L_{r}$ & $120 \mu \mathrm{H}$ & $C_{3}$ & $95 \mathrm{nF}$ \\
\hline$U_{D C}$ & $310 \mathrm{~V}$ & $R_{r}$ & $0.14 \Omega$ & $L_{f r}$ & $28.9 \mu \mathrm{H}$ \\
\hline$L_{i}$ & $102 \mu \mathrm{H}$ & $L_{f i}$ & $52.6 \mu \mathrm{H}$ & $C_{f r}$ & $120.9 \mathrm{nF}$ \\
\hline$R_{i}$ & $0.13 \Omega$ & $C_{f i}$ & $66.5 \mathrm{nF}$ & $C_{r}$ & $38.5 \mathrm{nF}$ \\
\hline$U_{b}$ & $400 \mathrm{~V}$ & $C_{1}$ & $93.7 \mathrm{nF}$ & $k_{r}$ & 0.14 \\
\hline$f_{s w}$ & $85 \mathrm{kHz}$ & $C_{2}$ & $123.2 \mathrm{nF}$ & & \\
\hline
\end{tabular}

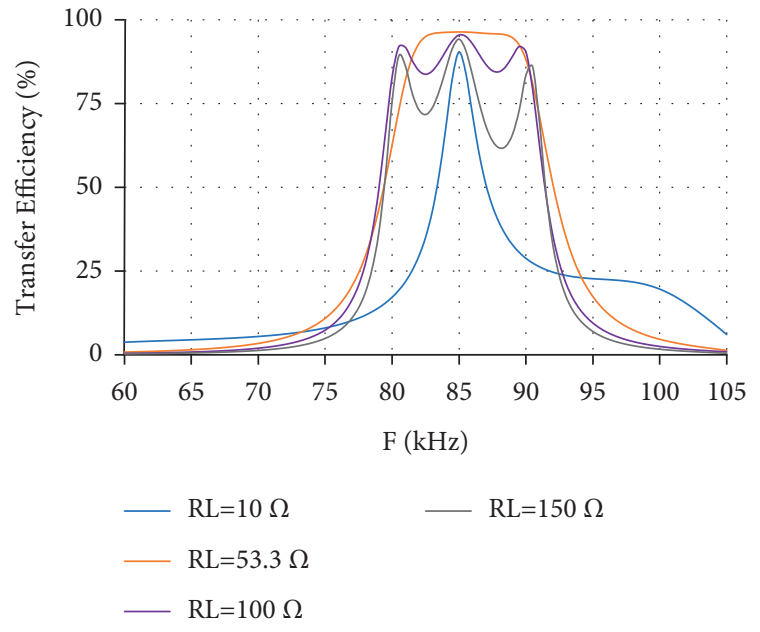

(a)

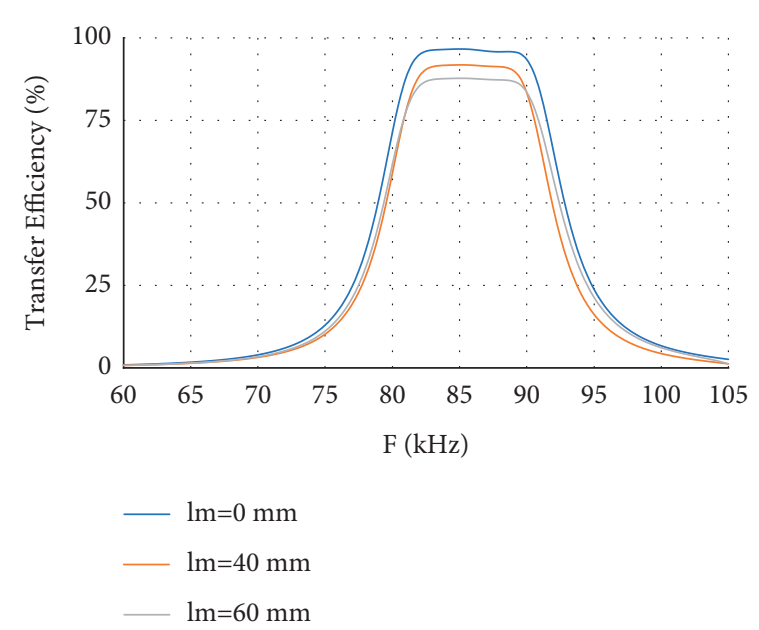

(b)

FiguRE 6: Frequency characteristics of the transfer efficiency. (a) $l_{m}=0 \mathrm{~mm}$ and $R_{L}$ is variation. (b) $l_{m}$ is variation and $R_{L}=R_{L . o p t}$.

where $R_{L . o p t}$ is called optimal impedance. Equations (2) and (3) show that the maximum transfer is only achieved when the equivalent impedance is equal to the optimal impedance value. Equation (2) is used to evaluate and estimate the theoretical maximum transfer efficiency shown in Figure 5. When $k_{r}=0.14$ and the quality factor $Q_{i}=429, Q_{r}=458$, the maximum theoretical transfer efficiency is about $94.6 \%$.

The parameter values of the compensation circuit are determined according to three conditions: the relationship of the resonant circuit, the output power, and the optimal load. The parameter values for a $1.5 \mathrm{~kW}$ dynamic charging system are shown in Table 2 [31].

In a WPT system, the transfer efficiency depends on the value of load impedance and coupling coefficient. Therefore, it is necessary to consider the effect of these parameters on transfer efficiency. Figure 6(a) shows frequency characteristics of the transfer efficiency when equivalent impedance $\left(R_{L}\right)$ increases from $10 \Omega$ to $150 \Omega$ and the receiver position $d_{r}$ is $0 \mathrm{~mm}, l_{m}$ is $0 \mathrm{~mm}$. The results show that transfer efficiency is the largest in the case of optimal impedance $\left(R_{L}=R_{L \text {.opt }}=53.3 \Omega\right)$. The maximum transfer efficiency is $94.6 \%$ and transfer efficiency is high in the frequency range $83 \mathrm{kHz}$ to $89 \mathrm{kHz}$. At other values of load impedance, the efficiency drops and drops rapidly in the vicinity of $85 \mathrm{kHz}$. Figure 6(b) shows frequency characteristics of the transfer efficiency when the receiver is the lateral misalignment and the value of load resistance is optimal load according to equation (3). The results show that the transfer efficiency is the largest in the case of no lateral misalignment $\left(l_{m}=0 \mathrm{~mm}\right)$. When the lateral misalignment increases, the transfer efficiency decreases.

Thus, in DWC systems, the transfer efficiency only reaches the maximum value at one load impedance value, known as the optimal impedance. However, the equivalent impedance $\left(R_{L}\right)$ will be changed due to the state of charge of the EV battery system. Furthermore, the optimum impedance value depends on the position of the receiver. Therefore, optimal impedance control is necessary to achieve maximum transfer efficiency in the DWC systems.

\section{Estimate Optimal Load and Proposed Secondary Side Control}

3.1. Estimation Coupling Coefficients from the Secondary Side. Analysis in Section 2.2 has shown that, in the DWC system, the coupling coefficient changes when the EVs move. Then, the optimal impedance to obtain maximum transfer efficiency also varies according to equation (3). Therefore, to realize the impedance matching control, the coupling coefficient must be estimated previously.

The coupling coefficient is estimated using only information from the receiving side proposed in this paper. From the equivalent circuit, as shown in Figure 4, in 


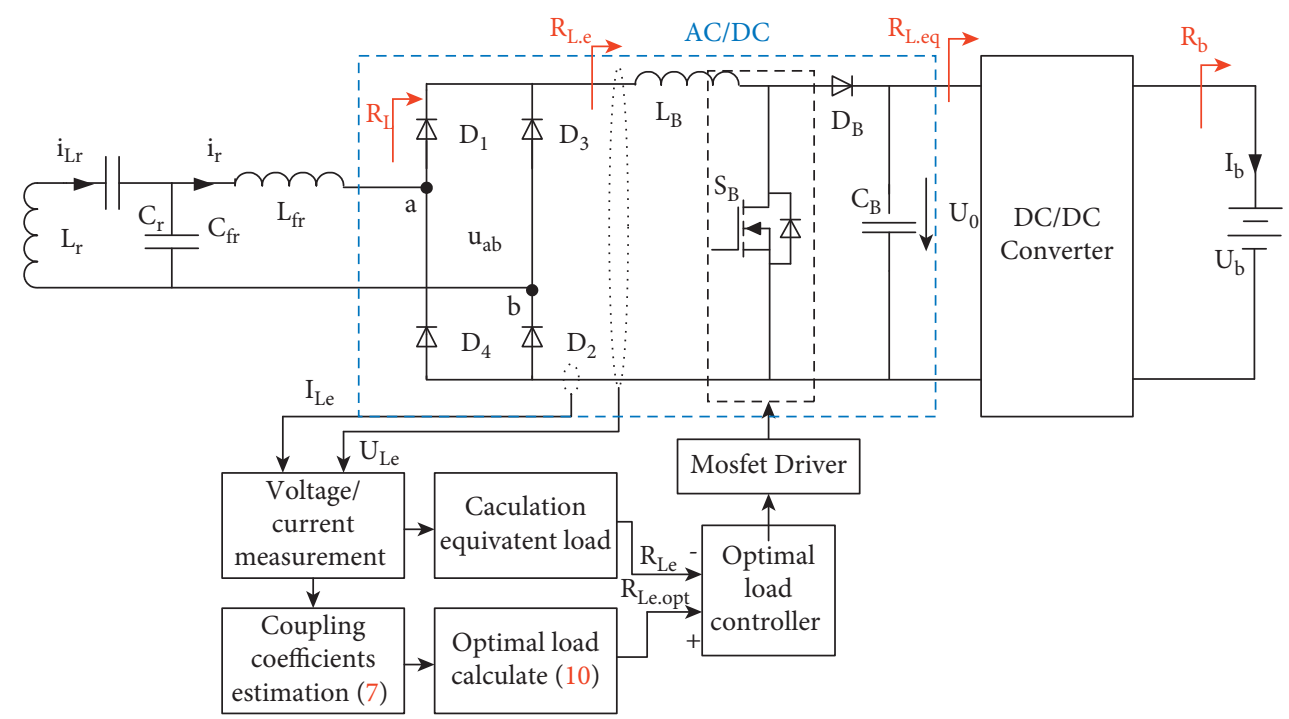

FiguRE 7: Closed-loop control block diagram.

the resonant condition, the current on the transmitting coils will be the same, and it can be calculated as follows [29]:

$$
I_{L 1}=I_{L 2}=I_{L 3}=I_{L i}=-\frac{U_{A B}}{1 /\left(j \omega C_{f i}\right)}=-j \omega C_{f i} U_{A B} .
$$

On the receiving side, the relationship among the parameters is

$$
\left\{\begin{array}{l}
\left(j \omega L_{r}+R_{r}+\frac{1}{j \omega C_{r}}\right) I_{L r}+\frac{1}{j \omega C_{f r}} I_{C f r}=j \omega M_{r} I_{L i}, \\
\left(j \omega L_{f r}+R_{L}\right) I_{r}=\frac{1}{j \omega C_{f r}} I_{C f r}, \\
I_{C f r}=I_{L r}-I_{r} .
\end{array}\right.
$$

From equations (4) and (5), if the value $U_{A B}$ is constant, the coupling coefficient can be estimated as

$$
k_{r}=\frac{L_{f r}}{U_{A B} \sqrt{L_{i} L_{r}}}\left[\frac{R_{r}}{\omega L_{f r}} U_{a b}+\omega L_{f r} I_{r}\right],
$$

where $U_{A B}$ is the RMS value of the output voltage of the fullbridge inverter and $U_{a b}$ and $I_{r}$ are the voltage and the current of equivalent load $R_{L}$.

However, the RMS current and voltage measurement will take error in the case of the nonsinusoidal or discontinuous current mode. Therefore, instead of measuring the RMS value, the output voltage $\left(U_{L e}\right)$ and current $\left(I_{L e}\right)$ in the DC side of the diode rectifier are measured to estimate the coupling coefficient:

$$
k_{r}=\frac{2 \sqrt{2 L_{f r}}}{\pi U_{A B} \sqrt{L_{i} L_{r}}}\left[\frac{R_{r}}{\omega L_{f r}} U_{L e}+\frac{8 \omega L_{f r}}{\pi^{2}} I_{L e}\right] .
$$

And then, according to equation (3), the optimal load is calculated.
3.2. Analysis of the Proposed Secondary Side Control. On the receiving side, a boost converter is used in impedance control as shown in Figure 7 . The equivalent input resistance is seen in the rectifier, which is regulated by the duty cycle $D$ of the boost converter [17]. The power losses of the Boost converter are ignored to simplify the analysis. Based on the power balance between input and output of the converter, the relationship between equivalent load is shown as follows:

$$
\begin{aligned}
R_{L} & =\frac{8}{\pi^{2}} R_{L . e}, \\
R_{L . e} & =(1-D)^{2} R_{\text {L.eq }} .
\end{aligned}
$$

Combining equation (3) with equation (8),

$$
R_{\text {L.e.opt }}=\frac{8}{\pi^{2}} \frac{\omega^{2} L_{f r}^{2}}{R_{r}} \sqrt{\frac{3}{3+k_{r}^{2} Q_{i} Q_{r}}},
$$

where $R_{L}, R_{L . e}, R_{L . e q}$ are equivalent load impedance values seen from the input of the full-bridge rectifier, boost converter, and DC/DC converter to load, respectively.

Thus, for the maximum transfer efficiency, instead of controlling $R_{L}$ value according to $R_{L \text {.opt }}$ value in equation (3), it is possible to adjust $R_{L . e}$ value according to $R_{\text {L.e.opt }}$ value in equation (10). From equations (9) and (10) through adjusting $D, R_{L . e}$ is regulated to $R_{\text {L.e.opt; }}$ then, the transfer efficiency is maximum.

Figure 7 shows the control diagram of the proposed DWC system. Since the transmitting side is considered as working individually, on the receiving side, $U_{L e}$ and $I_{L e}$ are measured. The total coupling coefficient is estimated by equation (7), the optimal load is calculated by equation (10) and feedback to the optimal load impedance controller.

\section{Simulation and Experiment Results}

To verify the proposed DWC system, a circuit simulation is performed where the topology is shown in Figure 1, and the parameters are shown in Tables 1 and 2. The transmitting 


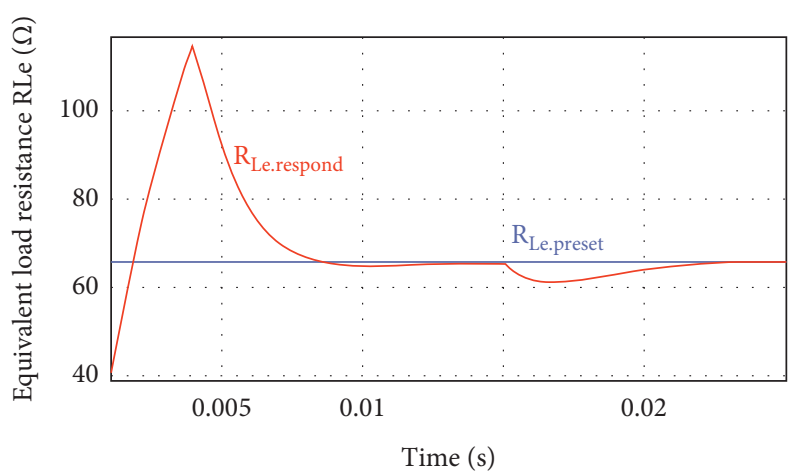

FIgURE 8: Simulation results of load impedance response according to a preset value.

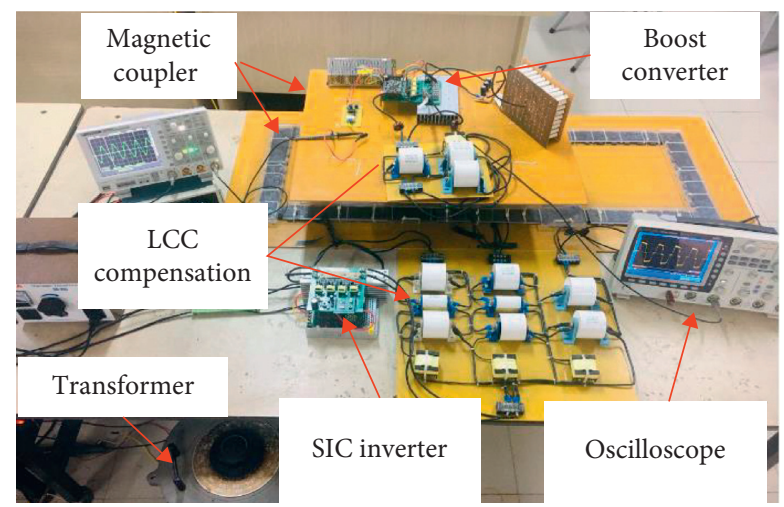

FIgURE 9: The DWC system experimental setup.

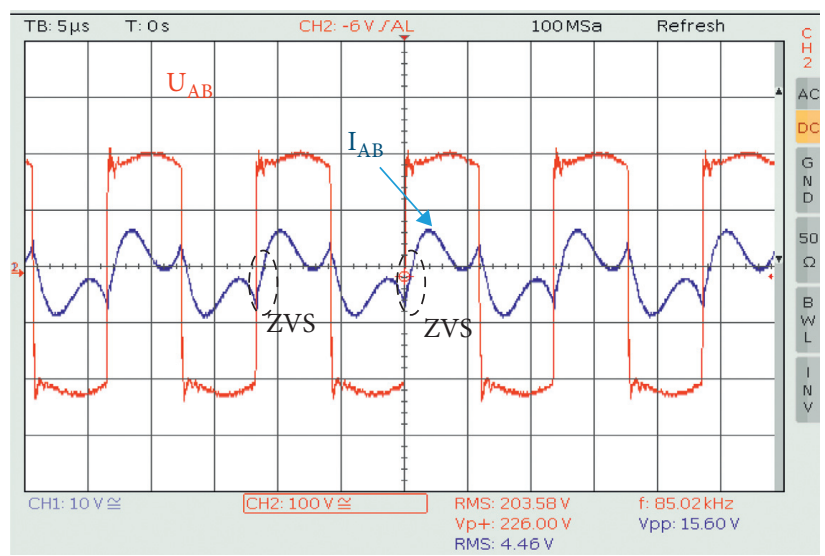

(a)

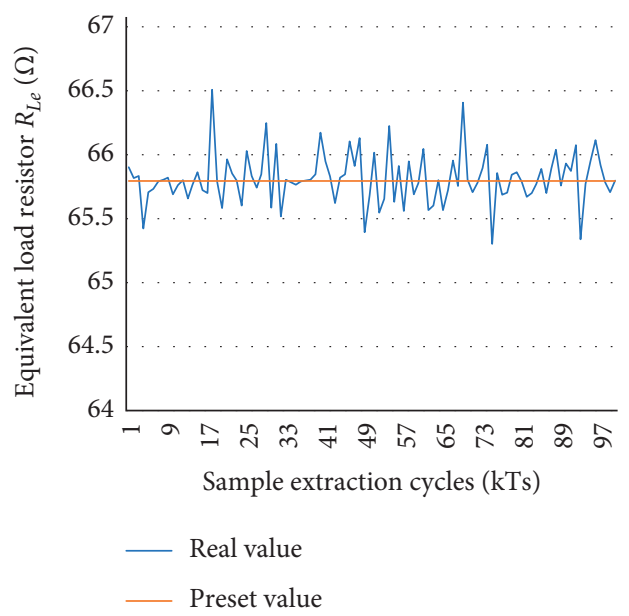

(b)

FIGURE 10: Experiment result at $0 \mathrm{~mm}$ position with no lateral misalignment. (a) Output voltage and output current of $85 \mathrm{kHz}$ inverter. (b) The measurement result of equivalent impedance $R_{L e}$.

coils are fixed in place, while the receiving coil is moving along the charging lane.

The estimation results of the total coupling coefficient are shown in Figure 3 (dot lines). The estimation errors of the coupling coefficient are less than $5 \%$.
The load response simulation results according to the preset value are shown in Figure 8, and the maximum response time is $0.007 \mathrm{~s}$ when the EV runs at a speed less than $40 \mathrm{~km} / \mathrm{h}$. This result shows that the optimal load controller responds to the system DWC requirements. 


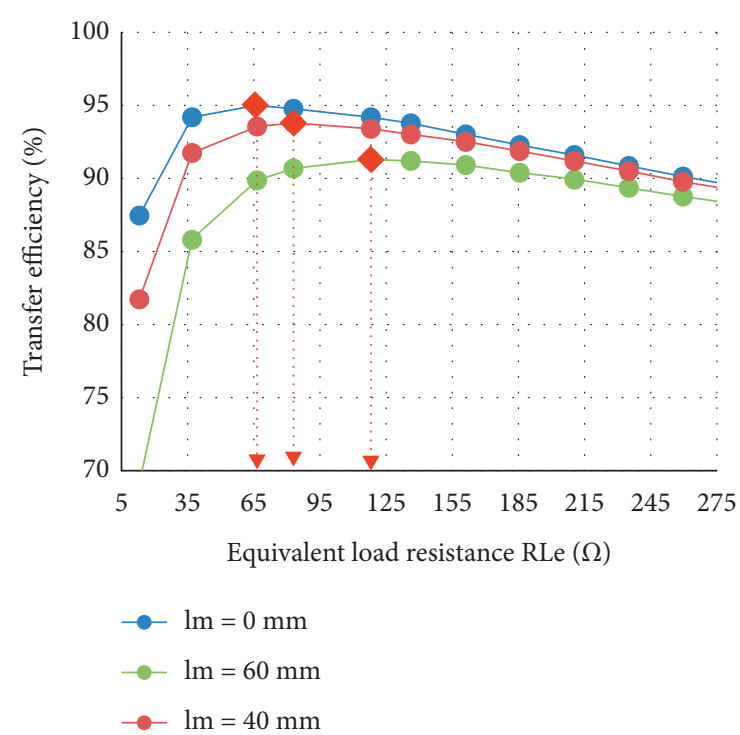

FIgURE 11: Transfer efficiency characteristic according to receiver position and equivalent impedance $\left(R_{L}\right)$.

As shown in Figure 9, an experimental setup in the laboratory environment has been built to verify the proposed control method. A $1.5 \mathrm{~kW}$ output power dynamic charging system is demonstrated. The coils and compensation circuit parameters as shown in Table 2. The stranded wire and ferrite are used to design the magnetic coupler. The polypropylene film capacitors are used to their low losses and high current bearing capability at high frequency. For the full-bridge inverter and boost converter, SIC C3M0280090D is used to obtain low switching power loss. The DWC system works at $85 \mathrm{kHz}$ according to the SEA J2954 standard. The input DC voltage is fixed at $310 \mathrm{~V}$, and the DC/DC converter and battery are replaced by a resistor with the resistance value changing from $10 \Omega$ to $250 \Omega$.

The experiment results in Figure 10 verify the LCC compensation circuit design and the impedance matching control ability of the boost converter. Figure 10(a) shows that all switching devices in the $85 \mathrm{kHz}$ inverter on the transmitting side obtain the ZVS condition thanks to the LCC compensation circuit design. Figure 10(b) shows the equivalent impedance $R_{L e}$ which is calculated from the measured voltage $U_{L e}$ and current $I_{L e}$ at the DC side of the diode rectifier in the receiving side. The results verify the impedance control ability of the boost converter. The equivalent impedance is kept at $65.7 \Omega$ when the load resistance changes from $10 \Omega$ to $275 \Omega$.

Figure 11 shows transfer efficiency characteristics according to receiver position and equivalent impedance in case of no impedance control. The experiment is performed when $d_{r}=0 \mathrm{~mm}, l_{m}$ changes from $0 \mathrm{~mm}$ to $60 \mathrm{~mm}$, and $R_{L e}$ increases from $10 \Omega$ to $275 \Omega$. As a result, when $l_{m}=0 \mathrm{~mm}$, the maximum transfer efficiency is $94.5 \%$ with the load impedance value of $65.7 \Omega$. In the case of $l_{m}=40 \mathrm{~mm}$ and $l_{m}=60 \mathrm{~mm}$, the maximum transfer efficiency is $93 \%$ and $91 \%$, with the load impedance value of $83 \Omega$ and $118 \Omega$,

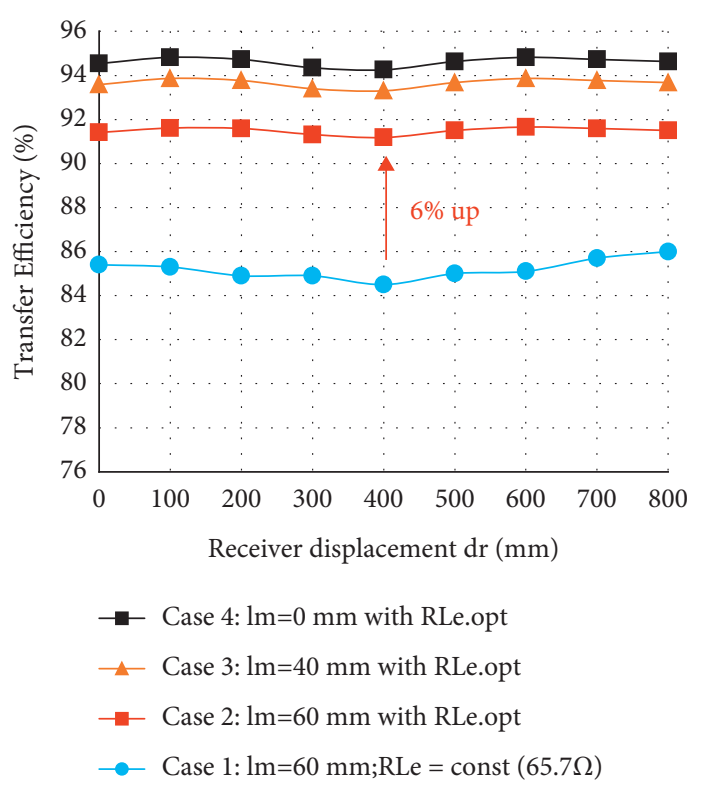

Figure 12: The transfer efficiency characteristics.

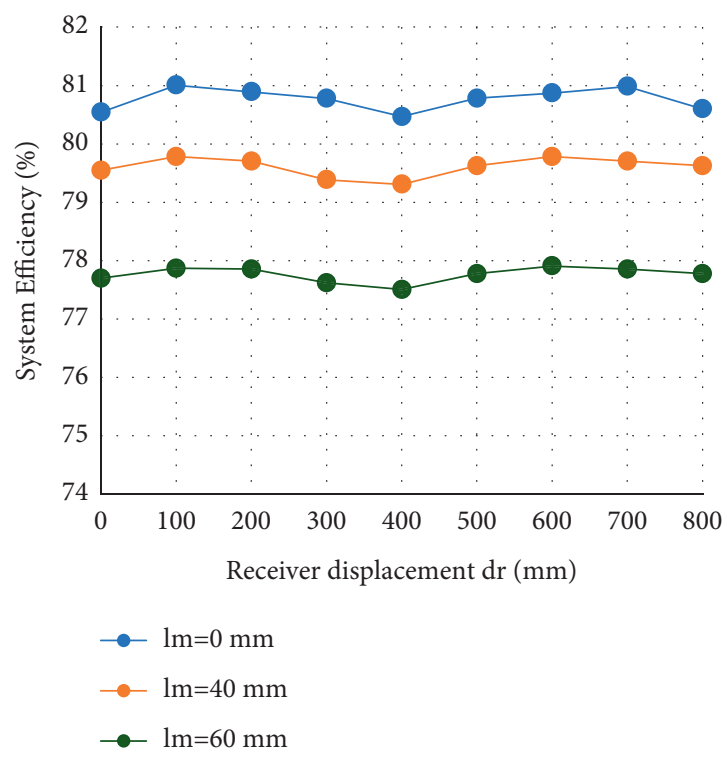

FIgUre 13: The system efficiency characteristics.

respectively. The results show that the optimal impedance value varies with receiver position. When the impedance is not controlled, the efficiency decreases when the load impedance value is different from the optimal impedance value.

Figure 12 shows the experiment transfer efficiency results in other cases. In case 1 (blue line), the receiver moves lateral misalignment according to the $y$-direction by $30 \%$ $\left(l_{m}=60 \mathrm{~mm}\right)$. The equivalent load impedance is kept as the designed value $\left(R_{L e . \text { opt }}=65.7 \Omega\right)$, without the optimal load estimation. In this case, the coupling coefficient is decreased, and then the load is designed to a value that is not the optimal one. Therefore, the transfer efficiency is reduced to $85 \%$. In case 2 (red line), the receiver moves lateral 
misalignment according to $y$-direction by $30 \%\left(l_{m}=60 \mathrm{~mm}\right)$. The optimal impedance is estimated and updated according to the receiver position. Then, the equivalent impedance is controlled by tracking to the new optimal impedance. In this case, the transfer efficiency increases up to over $91 \%$. Thus, when performing the optimal load-tracking control, the transfer efficiency is improved by $6 \%$ compared to the fixed optimum load impedance control. In case 3 (orange line) and case 4 (black line), the receiver moves lateral misalignment according to the $y$-direction by $20 \%$ and $0 \%$ $\left(l_{m}=40 \mathrm{~mm}\right.$ and $\left.0 \mathrm{~mm}\right)$, respectively. Equivalent impedance is controlled by tracking the optimal impedance. The transfer efficiency is $93.2 \%$ and $94.14 \%$, respectively. This result shows that when the optimal impedance tracking control is applied, the transfer efficiency is significantly improved.

The experimental results of the system efficiency from the DC input of the primary inverter to the DC output on the $R_{L e}$ load behind the secondary boost converter are shown in Figure 13. In case the receiver moves along the DWC lane and has lateral misalignment according to $y$-direction $0 \%$, $20 \%, 30 \%\left(l_{m}=0 \mathrm{~mm} ; l_{m}=40 \mathrm{~mm} ; l_{m}=60 \mathrm{~mm}\right)$, the system efficiency average is achieved as $80.7 \%, 79 \%$, and $77 \%$, respectively.

\section{Conclusions}

This paper proposes a maximum transfer efficiency tracking method in the DWC system of EVs. The proposed method can track the optimal impedance on the receiving side without any communication with the transmitting side to improve the transfer efficiency and stability in the dynamic charging system. This paper has not mentioned the charging process such as constant current charging and constant voltage charging. These issues will be addressed in future studies.

\section{Data Availability}

The data used to support the findings of this study are available from the corresponding author upon reasonable request.

\section{Conflicts of Interest}

The authors declare that they have no conflicts of interest.

\section{References}

[1] S. Li and C. C. Mi, "Wireless power transfer for electric vehicle applications," IEEE Journal of Emerging and Selected Topics in Power Electronics, vol. 3, no. 1, pp. 4-17, 2015.

[2] C. Panchal, S. Stegen, and J. Lu, "Review of static and dynamic wireless electric vehicle charging system," Engineering Science and Technology, an International Journal, vol. 21, no. 5, pp. 922-937, 2018.

[3] G. Buja, C.-T. Rim, and C. C. Mi, "Dynamic charging of electric vehicles by wireless power transfer," IEEE Transactions on Industrial Electronics, vol. 63, no. 10, pp. 6530-6532, 2016.
[4] L. A. Maglaras, F. V. Topalis, and A. L. Maglaras, "Cooperative approaches for dymanic wireless charging of electric vehicles in a smart city," in Proceedings of the 2014 IEEE International Energy Conference (ENERGYCON), pp. 1365-1369, Cavtat, Croatia, May 2014.

[5] S. Chopra and P. Bauer, "Driving range extension of EV with on-road contactless power transfer-A case study," IEEE Transactions on Industrial Electronics, vol. 60, no. 1, pp. 329-338, 2013.

[6] K. Hwang, J. Park, D. Kim et al., "Autonomous coil alignment system using fuzzy steering control for electric vehicles with dynamic wireless charging," Mathematical Problems in Engineering, vol. 2015, Article ID 205285, 14 pages, 2015.

[7] Y. Liu, R. Mai, D. Liu, Y. Li, and Z. He, "Efficiency optimization for wireless dynamic charging system with overlapped DD coil arrays," IEEE Transactions on Power Electronics, vol. 33, no. 4, pp. 2832-2846, 2018.

[8] Q. Zhu, L. Wang, Y. Guo, C. Liao, and F. Li, “Applying LCC compensation network to dynamic wireless EV charging system," IEEE Transactions on Industrial Electronics, vol. 63, no. 10, pp. 6557-6567, 2016.

[9] F. Lu, H. Zhang, H. Hofmann, and C. C. Mi, "A dynamic charging system with reduced output power pulsation for electric vehicles," IEEE Transactions on Industrial Electronics, vol. 63, no. 10, pp. 6580-6590, 2016.

[10] S. Zhou and C. Mi, "Multi-paralleled LCC reactive power compensation networks and their tuning method for electric vehicle dynamic wireless charging," IEEE Transactions on Industrial Electronics, vol. 63, no. 10, pp. 6546-6556, 2016.

[11] Y. Liu, P. A. Hu, and U. K. Madawala, "Maximum power transfer and efficiency analysis of different inductive power transfer tuning topologies," in Proceedings of the 2015 IEEE 10th Conference on Industrial Electronics and Applications (ICIEA), pp. 649-654, Auckland, New Zealand, June 2015.

[12] T. C. Beh, T. Imura, M. Kato, and Y. Hori, "Basic study of improving efficiency of wireless power transfer via magnetic resonance coupling based on impedance matching," in Proceedings of the 2010 IEEE International Symposium on Industrial Electronics, pp. 2011-2016, Bari, Italy, July 2010.

[13] Y. Lim, H. Tang, S. Lim, and J. Park, "An adaptive impedancematching network based on a novel capacitor matrix for wireless power transfer," IEEE Transactions on Power Electronics, vol. 29, no. 8, pp. 4403-4413, 2014.

[14] K. A. Kalwar, M. Aamir, and S. Mekhilef, "A design method for developing a high misalignment tolerant wireless charging system for electric vehicles," Measurement, vol. 118, pp. 237-245, 2018.

[15] P. Darvish, S. Mekhilef, and H. A. B. Illias, "A novel S-SLCLCC compensation for three-coil WPT to improve misalignment and energy efficiency stiffness of wireless charging system," IEEE Transactions on Power Electronics, vol. 36, no. 2, pp. 1341-1355, 2021.

[16] M. Fu, C. Ma, and X. Zhu, "A cascaded boost-buck converter for high-efficiency wireless power transfer systems," IEEE Transactions on Industrial Informatics, vol. 10, no. 3, pp. 1972-1980, 2014.

[17] Y. Huang, N. Shinohara, and T. Mitani, "Theoretical analysis on DC-DC converter for impedance matching of a rectifying circuit in wireless power transfer," in Proceedings of the 2015 IEEE International Symposium on Radio-Frequency Integration Technology (RFIT), pp. 229-231, Sendai, Japan, August 2015.

[18] R. Ruffo, V. Cirimele, M. Diana, M. Khalilian, A. L. Ganga, and P. Guglielmi, "Sensorless control of the charging process 
of a dynamic inductive power transfer system with an interleaved nine-phase boost converter," IEEE Transactions on Industrial Electronics, vol. 65, no. 10, pp. 7630-7639, 2018.

[19] W. X. Zhong and S. Y. R. Hui, "Maximum energy efficiency tracking for wireless power transfer systems," IEEE Transactions on Power Electronics, vol. 30, no. 7, pp. 4025-4034, 2015.

[20] Z. Li, K. Song, J. Jiang, and C. Zhu, "Constant current charging and maximum efficiency tracking control scheme for supercapacitor wireless charging," IEEE Transactions on Power Electronics, vol. 33, no. 10, pp. 9088-9100, 2018.

[21] M. Fu, H. Yin, X. Zhu, and C. Ma, "Analysis and tracking of optimal load in wireless power transfer systems," IEEE Transactions on Power Electronics, vol. 30, no. 7, pp. 39523963, 2015.

[22] H. Li, J. Li, K. Wang, W. Chen, and X. Yang, "A maximum efficiency point tracking control scheme for wireless power transfer systems using magnetic resonant coupling," IEEE Transactions on Power Electronics, vol. 30, no. 7, pp. 39984008, 2015.

[23] T.-D. Yeo, D. Kwon, S.-T. Khang, and J.-W. Yu, "Design of maximum efficiency tracking control scheme for closed-loop wireless power charging system employing series resonant tank," IEEE Transactions on Power Electronics, vol. 32, no. 1, pp. 471-478, 2017.

[24] N. T. Diep, N. K. Trung, and T. T. Minh, "Maximum efficiency in the dynamic wireless charging systems of electric vehicles," in Proceedings of the 2019 10th International Conference on Power Electronics and ECCE Asia (ICPE 2019-ECCE Asia), pp. 1-6, Busan, South Korea, May 2019.

[25] D. Kobayashi, T. Imura, and Y. Hori, "Real-time coupling coefficient estimation and maximum efficiency control on dynamic wireless power transfer for electric vehicles," in Proceedings of the 2015 IEEE PELS Workshop on Emerging Technologies: Wireless Power (2015 WoW), pp. 1-6, Daejeon, South Korea, June 2015.

[26] K. Hata, T. Imura, and Y. Hori, "Dynamic wireless power transfer system for electric vehicles to simplify ground facilities-power control and efficiency maximization on the secondary side," in Proceedings of the 2016 IEEE Applied Power Electronics Conference and Exposition (APEC), pp. 1731-1736, Long Beach, CA, USA, March 2016.

[27] X. Dai, X. Li, Y. Li, and A. P. Hu, "Maximum efficiency tracking for wireless power transfer systems with dynamic coupling coefficient estimation," IEEE Transactions on Power Electronics, vol. 33, no. 6, pp. 5005-5015, 2018.

[28] V. Jiwariyavej, T. Imura, and Y. Hori, "Coupling coefficients estimation of wireless power transfer system via magnetic resonance coupling using information from either side of the system," IEEE Journal of Emerging and Selected Topics in Power Electronics, vol. 3, no. 1, pp. 191-200, 2015.

[29] J. Yin, D. Lin, T. Parisini, and S. Y. Hui, "Front-end monitoring of the mutual inductance and load resistance in a series-series compensated wireless power transfer system," IEEE Transactions on Power Electronics, vol. 31, no. 10, pp. 7339-7352, 2016.

[30] Y.-G. Su, H.-Y. Zhang, Z.-H. Wang, A. Patrick Hu, L. Chen, and Y. Sun, "Steady-state load identification method of inductive power transfer system based on switching capacitors," IEEE Transactions on Power Electronics, vol. 30, no. 11, pp. 6349-6355, 2015.

[31] N. T. Diep, N. K. Trung, and T. T. Minh, "Wireless power transfer system design for electric vehicle dynamic charging application," International Journal of Power Electronics and Drive Systems, vol. 11, no. 3, p. 1468, 2020. 